\title{
1 \\ DEKONSTRUKSI KESAKRALAN DUNIA PEWAYANGAN : Sebagai Peninggalan Adiluhung melalui Manyura
}

Taufik Nurhadi

\begin{abstract}
Abstrak
The purpose of this study is to obtain the results of descriptions and explanations on puppet world deconstruction which is sacred and sublime masterpiece through the creative work of fiction, Manyura written by Yanusa Nugroho. The results of this literature review based on the approach prove that deconstruction in Manyura produce: (1) the lawsuit against submission of puppet history, (2) the degradation of intensity characterizations, and (3) demoralization figure Yudhishthira. The three forms of deconstruction express the social criticism to the behavior of Indonesian politics, especially in the Era of ORBA.
\end{abstract}

Keywords: deconstruction, puppet, submission, degradation, demoralization.

\section{PENDAHULUAN}

Pendekonstruksian dunia pewayangan sebagai peninggalan adiluhung merupakan bagian dari hasil kreativitas pengarang yang bersifat imajiner. Pendekonstruksian itu merupakan bentuk keberanian pengarang mengaitkannya dengan dunia fakta yang berisi kritik sosial dan carut-marut dalam politik-pragmatis. Semua itu terepresentasi melalui karya Yanusa NugroHo yang berwujud novel yang berjudul Manyura.

Manyura merupakan karya fiksi yang bersifat kontroversial. Karya fiksi ini berisi hibridasi antara dunia pewayangan dan dunia fakta. Hibridasi ini mengindikasikan adanya pergeseran konstruksi dari kisah mitologis yang sakral ke karya fiksi-kontemporer. Pemanfaatan dunia pewayangan, khususnya epos Mababharata pasca-Bharatayuda dikreasikan dengan dunia fakta yang penuh dengan ketimpangan sosial dan kecarutmarutan dunia politik yang penuh intrik.

Bagaimanakah dengan Manyura sebagai judul? Perlu diketahui bahwa tidak ada satu pun kata "Manyura" muncul dalam teks novel tersebut. Dalam dunia pewayangan, "Manyura" adalah istilah pathetan dalam pentas wayang kulit semalam suntuk, yaitu bagian puncak atau akhir pertunjukan. Bagian inilah merupakan penentuan nasib para tokoh atau pelaku dalam cerita yang dihadirkan. Dari sisi inilah NugROHO mendekonstruksi kesakralan dunia pewayangan yang hitam putih melalui karya majinasinya, Manyura.

Pendekonstruksian itu sendiri dimaksudkan sebagai upaya pengurangan atau penurunan intensitas konstruksi itu sendiri. (Lih. Ratna, 2005:250). Dengan demikain, pendekonstruksian dunia pewayangan yang sakral berarti upaya pengarang menurunkan intensitas konstruksi pewayangan, khususnya epos Mababarata yang dianggap mapan sebagai dunia yang secara kolektif disikapi memiliki kesakralan yang tidak dapat diubah. Selama ini terdapat kesadaran kolektif bahwa dunia pewayangan adalah dunia hitam putih. Tidaklah mengherankan apabila kemampuan YANUSA NugrOHO dalam berkreasi melalui dunia pewayangan membuat Bre Redana, wartawan Kompas kagum. Dalam 
pengantar novel Manyura, Bre Redana menganggap bahwa YANusA NugROHO memiliki kebebasan urban di dalam dirinya sehingga dia bebas mengembangkan imajinasinya secara kreatif dengan mengacak-acak kesakralan dunia pewayangan.

Yang menjadi permasalahan adalah macam dekonstruksi apakah yang terdapat dalam Manyura sebagai bentuk kebebasan urban sosok YANuSA NugroHo dalam berkreasi. Dalam hal ini, perlu diberikan catatan bahwa dekonstruksi dunia pewayangan pada dasarnya sudah dilakukan sejak dulu. Dalam dunia pedalangan, misalnya, pembaruan juga telah dilakukan sejak zaman dalang Ki Nartosabdho sampai ke dalang-dalang muda masa kini sehingga ada di antaranya disebut "dalang edan" atau "dalang gendheng". Hal ini mengindikasikan adanya sikap pemberontakan mereka terhadap pakem. kalau wayang kulit umumnya pertunjukan diawali dengan jejer, pada pertunjukan Ki Nartosabdho bisa langsung diisi dengan goro-goro, dagelan, dan atau suasana kelucuan. Pada zaman Wali pun pembaruan itu ada dengan menghadirkan tokoh punakawan yang melegenda dalam budaya kita. Meskipun demikian, dekonstruksi dunia pewayangan yang dilakukan pendahulunya tidak seutuh dekonstruksi YANUSA yang menyangkut sejarah pewayangan, penokohan, dan moral. Dekonstruksi sejarah pewayangan berkaitan dengan masalah subfimisme sejarah pewayangan, dekonstruksi penokohan berhubungan dengan degradasi intensitas penokohan, dan dekonstruksi moralberkenaan dengan demoralisasi.

Berdasarkan paparan tersebut, ada tiga permasalahan yang akan diangkat dalam pembahasan ini ialah

(1) Bagaimanakah dekonstruksi subfimisme se jarah pewayangan dalam Manyura?

(2) Bagaimanaka degradasi intensitas penokohan dalam Manyura?

(3) Bagaimanakah demoralisasi yang terepresentasi melalui Manyura?
Tujuan pembahasannya adalah untuk memperoleh deskripsi dan penjelasan tentang subfimisme sejarah pewayangan, degradasi intensitas penokohan, dan imoralitas. Manfaat pembahasannya ialah agar pembaca bisa menghambil hikma dan keteladanan yang tersarikan dalam Manyura tentang konsistensi kebenaran sejarah, intensitas penokohan yang etis, dan keberpihakan terhadap nilai moral.

Strategi pembahasannya berdasarkan pendekatan kepustakaan. Penyediaan datanya didasarkan pada teks dalam Manyura yang mengindikasikan adanya ketiga macam dekonstruksi tersebut. Agar diperoleh penjelasan yang memadai dan reliabel, dimanfaatkan data pembanding yang bersumber pada epos Mahabharata (2002) yang disusun oleh Nyoman S. PenDIT dan Bharatayuda (2007) yang disusun oleh WAWAN SUSETYA.

\section{SUBMISIFME SEJARAH PE- WAYANGAN}

Dekonstruksi kesakralan dunia pewayangan yang dilakukan oleh YANUSA NUGROHO melalui Manyura berupa gugatan terhadap submisifme sejarah pewayangan. Submisifme berasal dari bahasa Inggris submisive (adj.'patuh', rendah diri', 'menyerah' atau 'mengalah') dan ism (n. 'ajaran', 'paham', 'perbuatan', atau 'keadaan'). Submisifme berarti 'suatu keadaan penyesuaian diri terhadap keinginan yang lain.' (ANSHARI, 1996:675; Salim, 2002: 1000,1956). Pengertian "keinginan yang lain" dalam Manyura adalah 'keinginan penguasa'. Dengan demikian, submisifme sejarah dalam dunia pewayangan diartikan 'terdapat penyesuaian pengungkapan fakta terhadap keinginan penguasa'. Melalui kenyataan ini, YANUSA NugROHO telah memanfaatkannya untuk menggugat submisifme sejarah pewayangan dengan memasukkan ide-idenya melalui Manyura.

Upaya Yanusa NugroHo menggugat submisisme dunia pewayangan pada dasarnya tidak terlepas pada kesadaran kolektif sebagian 
masyarakat yang menganggap dunia wayang sebagai dunia hitam putih. Dalam epos $\mathrm{Ma}$ babharata, Pandawa sebagai pihak putih yang melambangkan kebaikan, kebenaran, dan kebajikan; sebaliknya Kaurawa sebagai pihak hitam yang melambangkan kejahatan, keserakahan, dan keangkaramurkaan. Hal itu berarti sejarah wayang telah terkonstruksi secara mapan seiring dengan kesadaran masyarakat yang menerima konstruksi tersebut sebagai suatu kebenaran.

Kesadaran kolektif tersebut didekonstruksi oleh Yanusa NugroHo melalui Manyura. Keberadaan hitam putih dalam dunia wayang diturunkan intensitas kebinerannya melalui cela-cela yang memungkinkan dapat dimanfaatkan NuGROHO untuk memaksakan ide-ide kreatif-imajinatifnya. Untuk mewujudkannya, kebenaran realita sejarah pewayangan dipertanyakan oleh NugrOHO melalui kutipan berikut.

1. Ah, sejarah. Makhluk apakah dia, yang tak bisa berbuat apa-apa kecuali mencatat peristiwa dalam diam. Dia begitu lunak, sehingga sering kali hanya mau berlindung pada ketiak para penguasa (Manyura, hlm.1).

Kata "diam" dan "lunak" menunjukkan bahwa fakta sejarah dapat bergeser sesuai dengan selera penguasa seiring kepasifannya dalam mengungkapkan kebenaran sejarah. Hal ini diperjelas dalam perkataan "seringkali hanya berlindung pada ketiak para penguasa."

Ketimpangan dalam mengungkapkan fakta yang lebih condong untuk kepentingan penguasa diungkapkan NuGROHO seperti pada nukilan berikut.

2. Sejarah adalah makhluk pengecut yang sering kali ketakutan memandang mata pedang para kesatria dan pembesar istana. Dengan dalih ketakberdayaannya, sejarah hanya bisa menangis memandangi manusia-manusia berkeringat yang kalah oleh kekuasaan (Manyura, hlm.1)

Ketidakberanian penulis sejarah mengungkap- kan fakta pada sisi-sisi yang tidak menguntungkan penguasa terlihat pada sebutan sejarah sebagai "makhluk pengecut" pada (2).

Kebenaran fakta tidak terungkap dalam sejarah bila menyangkut pihak yang termajinalkan. Kepahlawanan para prajurit dari kalangan bawah tidak banyak diungkapkan, justru yang ditonjolkan kepahlawanan para ksatria di kalangan istana. Hal ini secara implisit terlukis pada kutipan (3).

3. Dengan gaya aristokratnya, sejarah hanya bisa melirik para prajurit yang perutnya koyak oleh tombak, atau dadanya hancur terinjak kaki gajah, kemudian mendesahkan ungkapan klise: zaman memang tak pernah adil bagi yang papa (Manyura, hlm.1-2).

Teks tersebut pada dasarnya sebagai gugatan terhadap sejarah wayang yang memiliki konsep kepahlawanan yang diidentikkan dengan kasta ksatria. Mereka adalah para ksatria yang hidup di kalangan istana dan masih keturunan atau kerabat raja. Misalnya, Arjuna, Bhima, Bhisma, dan lain-lain sering ditonjolkan kegagahan dan keberaniannya sehingga diberikan predikat pahlawan. Namun, kegagahan, keberanian, dan kesetiaan prajurit kalangan bawah tidak pernah tersentuh oleh predikat pahlawan.

Pemikiran NugroHo itu pada dasarnya dapat dimaklumi mengingat dia pernah hidup pada peralihan ORLA ke ORBA dan dari ORBA ke Reformsi. Pada masa ORBA banyak fakta sejarah yang dibengkokkan. Penulisan sejarah lebih banyak berkompromi dengan penguasa. Ketika terjadi peralihan dari ORBA ke Reformasi, sejarah Indonesia mulai digugat. Keberpihakan sejarah terhadap penguasa terlihat adanya upaya penonjolan tokoh Soeharto sebagai pahlawan dalam menumpas G 30 S PKI. Dalam sejarah kemerdekaan, Soeharto juga ditokohkan dalam Serangan Oemum Yogyakarta.

Sikap kritis terhadap kelemahan sejarah juga diperuntukkan untuk keperluan mencari cela untuk memasukkan ide-idenya melalui kreasi imajinatifnya dalam Manyura. Kelemahan sejarah berarti celah yang dapat dimasuki untuk 
membedah sejarah pewayangan. Submisifme sejarah pewayangan merupakan simbol kesadaran kolektif sebagian masyarakat. Kekuasaan dalam dunia pewayangan demikian suci dan sakral.

Dalam dunia pewayangan konvensional, khususnya epos Mahabharata, penobatan Yudhistira sebagai raja di Hastinapura pascaperang Bharatayudha dilukiskan melalui proses kontemplasi terhadap hakekat penguasa yang bersandarkan pada darma. Sikap menolak Yudhistira untuk dinobatkan sebagai raja karena merasa berdosa terhadap banyaknya korban manusia pascaperang. Dia dilukiskan calon pemimpin yang ideal yang tahu diri terhadap apa yang pernah diperbuatnya. Sikap merasa berdosa terhadap langkah-langkahnya sebagai pemimpin perang dinetralisasi melalui legitimasi pembenaran oleh saudara-saudaranya, Dristarasta, Widura, dan bahkan Bhisma. (Lih. PENDIT, 2004:366). Kenginannya untuk sunyasa ${ }^{1}$ akhirnya batal. Pelukisan penguasa dalam dunia pewayangan yang demikian suci dan sakral menjadi kriteria yang tidak dapat ditawar-tawar lagi. Kesadaran kolektif inilah yang dicobah dibedah oleh NugroHo agar dapat leluasa memanfaatkan dunia pewayangan, khususnya epos Mahabharata untuk memasukkan ide-idenya melalui Manyura. Pembedahan awal melalui kelemahan sejarah seperti dilukiskan pada kutipan (1) s.d. (3) dimanfaatkan NugrOHO sebagai langkah dasar pembedahan-pembedahan lebih lanjut terhadap kesakralan dunia wayang yang bersifat hitam-putih.

Perkataan kunci sebagai dasar pembedahan kesakralan dunia perwayangan yang diidentikkan dengan sejarah dapat dilihat pada kutipan berikut.

4. “...Memang, sekali lagi, sejarah mencatatnya demikian. Mungkin kali ini sejarah memang benar, tetapi yang jelas, bukan satu-satunya kebenaran..." (Manyura, hlm.2).

\section{Sanyasa adalah penyucian diri terhadap dosa dengan bertapa di Sungai Gangga. (PENDIT, 2004:368).}

Kutipan tersebut jelas menunjukkan bahwa kesakralan pengisahan epos Mahabharata masih bisa didekonstruksi demi pengekspresian ide-idenya melalui karya fiksinya itu.

Meskipun demikian, apapun alasannya, prolog tersebut cukup mengganggu terhadap pengisahan cerita novel tersebut. selain itu, gugatan terhadap sejarah pewayanga menunjukkan sikap setengah hati YANUSA NugrOHO dalam melakukan pembaruan yang kontroversial. Keberadaan prolog sebagai dasar awal pembenaran dekonstruksi epos Mababharata tidak harus dilakukan demi kewajaran pengisahan.

\section{DEGRADASI INTENSITAS PENO- KOHAN}

Dalam karya narasi, terdapat kelaziman adanya tokoh tertentu sebagai tokoh yang dominan dalam pengisahan. Tokoh tersebut lazim disebut tokoh utama. Dalam dunia pewayangan, penonjolan terhadap tokoh-tokoh tertentu cenderung diberikan pada tokoh-tokoh yang mewakili tokoh-tokoh putih, seperti misalnya tokoh-tokoh Pandawa dalam Mahabharata. Keberadaan Yudhistira, Bhima, dan Arjuna demikian dominan. Namun, dalam Manyura tokoh marjinal seperti Aswatama justru ditonjolkan dalam pengisahan, selain tokoh Yudhistira. Penyetaraan tokoh Aswatama terhadap tokoh Yudhistira mengisyaratkan adanya degradasi intensitas penokohan tokoh Yudhistira yang dalam dunia pewayangan selalu ditonjolkan ketokohannya setara dengan tokoh-tokoh pandawa lainnya.

Pelukisan tokoh Aswatama yang ditonjolkan pengarang tidak sekadar kehadirannya dihampir semua bab, juga pelukisan secara dramatis suasana psikologis tokoh tersebut yang menjadi orang termajinalkan dari pihaknya kalah perang. NugroHo mencoba menganalisis permasalahan pascaperang melalui pandangan dari pihak yang kalah perang, dalam hal ini diwakili Aswatama.

5. Wahai sang waktu, apa sebenarnya yang se- 
dang kau lakukan saat ini? Mengapa tidak pernah kau rasakan kelelahan dalam menjalani kehidupan di dunia ini? Kau berjalan dan berjalan, mengikuti setiap denyut kehidupan, menyeret dan membawa siapa pun ke dalam dekapanmu. Tak satu pun yang mampu menolakmu. Tak satu pun mampu menandingi kekuatanmu. Mungkinkah engkau adalah kehidupan itu sendiri? Jika memang demikian, mengapa bahkan yang telah mati pun masih saja kau seret dan kau lumatkan? Apakah engkau adalah kehidupan dan kematian itu sendiri? (Manyura, hlm.2)

Perenungan tokoh Aswatama tersebut tampaknya perenungan yang tidak selazimnya muncul pada tokoh yang sama dalam dunia pewayangan yang secara konvensional identik dengan tokoh jahat. Perenungan itu selayaknya merupakan perenungan yang dilakukan tokoh bijak yang melihat prilaku manusia yang tidak wajar dan di luar nilai-nilai perikemanusiaan. Hal itu berarti, NugROHO mencoba melihat dari sudut pandang dari tokoh yang dalam dunia wayang termarjinalkan. Perhatikan petikan berikut ini.

6. Hatinya pedih menyaksikan kehancuran negaranya. Di sinilah dia dibesarkan. Sokalima, tempat yang sejak kecil dikenalnya itu, terseret kehancuran bersama matinya Dorna. Para pengikut setia, bahkan penduduk di sekitarnya, seakan tak mengenalnya lagi. Mereka bukan saja mencemooh, namun dengan terang-terangan mempermainkan ayah yang sangat dicintainya. (Manyura, hlm.3)

NugROHO tampak sekali memunculkan Aswatama sebagai tokoh yang sakit hati karena, ditinggal oleh orang-orang yang dulunya menghormati dirinya dan keluarganya ketika masih berkuasa. Berbekal pelukisan Aswatama sebagai tokoh yang sakit hati dan termajinalkan, dia menciptakan konflik-konflik melalui tokoh tersebut. Sampai akhir cerita, Aswatama ditokohkan sebagai tokoh provokator Dalam pengisahan pun pemunculannya demikian dominan. Asal-usul Aswatama dan keluarganya, perasaan-perasaan hatinya terhadap wanita yang diinginkannya, kepribadian, langkah-langkah balas dendam dilukiskan dalam Manyura.

Tokoh-tokoh lain seperti Arjuna dan Bima dalam dunia pewayangan konvensional yang memiliki peran yang menonjol terdegradasi intensitas perannya dalam Manyura; dan sebaliknya Sasikirana, anak Gatotkaca justru menunjukkan peningkatan intensitas kehadiran dalam pengisahan. Tampak sekali NugrOHO memunculkan tokoh ini karena dianggap sisi yang dapat digarap karena perannya yang kurang menonjol di dunia pewayangan konvensional. Tokoh Sasikirana dimunculkan sebagaii tokoh yang terprovokasi oleh Aswatama. Demikian pula Yudhistira, tokoh ini sebenarnya selalu ternomorduakan dibandingkan tokoh pandawa seperti Arjuna dan Bima. Justru dalam Manyura, tokoh Bima dan Arjuna ternomorduakan dibandingkan Yudhistira.

\section{Demoralisasi}

Demoralisasi dalam Manyura terlihat pada pergereseran perwataan sebagian tokoh-tokohnya. Tokoh-tokoh tersebut di antaranya Yudhistira, Aswatama, Sasikirana, Drupadi, dan Srikandi. Tokoh lain tampaknya tidak terlalu mengalami perubahan yang terlalu destruktif.

Di antara tokoh-tokoh itu, terdapat dua tokoh yang dianggap sebagai tokoh kunci, yaitu Yudhistira dan Aswatama. Sama halnya dengan fenomen suksesi kepemimpinan yang memberikan harapan baru rakyat terhadap perbaikan nasibnya. Pendemoralisasian melalui penggeseran perwatakan tokoh Yudhistira dari tokoh yang santun, jujur, tidak suka berbohong menjadi tokoh yang kasar, otoriter, tidak peka, egois, dan seperangkat perwatakan buruk lainnya.

Posisi Yudhistira sebagai tokoh yang baru dinobatkan sebagai penguasa di Hastinapura pascaperang Bharatayhuda dimanfaatkan NugROHO untuk mendemoralisi tokoh tersebut demi senario pengisahan dalam Manyura. 
Tindakan kursif yang dilakukan Yudhistira dalam menjalankan pemerintahan pada dasarnya merupakan perwujudan demoralisasi tokoh bersangkutan.

7. Belum genap satu purnama, Prabu Yudhistira telah mengganti hampir seluruh pejabat istana hingga ke desa-desa. Pembersihan itu dilakukan dengan tegas dan telak. (Manyura, hlm.10-11)

Merekonstruksi pejabat pemerintahan yang dilakukan Yudhistira pada dasarnya untuk mengamankan dan memperkuat kedudukannya. Sikap Yudhiatira yang terwujud dalam menjalankan kebijakan pemerintahannya tersebut menunjukkan pergeseran perwataan Yudhistira yang dalam dunia pewayangan konvensional sebagai tokoh yang penuh pertimbangan sebelum bertindak. Dalam epos Mababarata yang disusun Nyoman S. Pendit, dia dalam menjalankan pemerintahannya selalu meminta nasihat dan persetujuan Drestarata. (Lih. PENDIT, 2004:371). Demoralisasi tokoh yang dilakukan NugrOHO tersebut pada dasarnya sebagai langkah mewujudkan idenya tentang fenomen rasa takut penguasa baru terhadap ancaman kedudukannya. Rekonsruksi pejabat dalam struktur pemerintahannya yang cenderung berdasarkan keberpihakan mengekspresikan krisis moral pemimpin pascakekerasan.

Kelaziman pascaperang berdampak krisis ekonomi diikuti kebijakan pemerintah yang tidak populer. Untuk mengangkat ide ini dalam novelnya, NugroHo mendemoralisasi tokoh Yudhistira sebagai penguasa yang menerapkan kebijakan ekonomi yang tidak berbasis kepentingan rakyat. Perhatikan kutipan berikut.

8. Perhitungan pajak dan upeti dibuka. Mereka yang tak mampu melaporkan kekayaan negara dengan benar, atau tak memiliki catatan apa pun, menerima nasib di tiang gantungan. Rakyat bersorak menyambut ketegasan raja baru mereka (Manyura, hlm. 10-11).

Meskipun pada awalnya masyarakat menyambut baik kebijakan ekonomi tersebut, lama kelamaan dampak itu terasa bagi rakyat kecil. Rakyat yang sudah menderita akibat dampak perang, semakin menderita karena terbebani pajak yang nilainya di luar kemampuannya. Akibatnya terjadi krisis kepercayaan terhadap pemerintahan Yudhistira.

9. Wilayah-wilayah kecil yang semula mengelu-elu dan mengharapkan cahaya dari penguasa baru Hastina, ternyata kecewa. Upeti yang ditetapkan Prabu Kalimataya dirasakan terlalu berat (Manyura, hlm. 52).

Selain kebijaksanaan pemerintah tentang pajak, pemerintah Yudhistira juga melakukan kebijakan menghidupkan roda pemerintahan dengan melakukam pembangunan infrastruktur yang hancur akibat perang maupun yang perlu diadakan. Untuk melaksanakan kebijaksanaan ini, rakyat direkrut sebagai relawan untuk memperbaikiki sarana jalan dari Hastinapura ke mancanegara, pelabubuhan-pelabuhan dagang, dan jalur-jalur ke berbagai desa. Perhatikan sikap masyarakat kecil yang terkena dampak kebijakan tersebut.

10. "Kyai-ne... kalau saya tidak salah tangkap... kok, rasanya, ini saya, Kyai, kok, seperti kerja paksa?" ucap seorang lelaki tua, namun berbadan tegap itu kepada Semar. (Manyura, hlm. 13).

Kebijakan tersebut tidak sekadar tuntutan terhadap tenaga fisik, juga finansial seperti kutipan berikut.

11. "Betul Kyai-ne, saya Cuma punya kambing, lantas apa, demi negara, kambing saya yang bungkring itu juga diserahkan? Lha, kami sekeluarga makan apa?" tambah yang lain lagi (Manyura, hlm.13).

Kebijakan Yudhistira dalam menjalankan pemerintahan tersebut pada dasarnya sebagai kritik terhadap pemikiran modernisme. Pemerintah melakukan langkah-langkah rasional dengan membangun insfrastruktur agar perekonomian berjalan dengan baik. Untuk mencapainya, semua potensi dikerahkan. Namun, konsep modernisme dalam pelaksanaannya ternyata sering menimbulkan permasalahan baru dan 
berdampak negatif. Akibat yang terjadi adalah penderitaan yang berkepanjangan dialami masyarakat kecil yang semakin termarjinalkan.

Demoralisasi Yudhistira sebagai pemimpin yang tidak bijaksana juga dimanfaatkan NugROHO untuk mengemukakan isu sektarian. Tampaknya dia mengangkat permasalahan ini sebagai dampak kebijakan Yudhistira sebagai penguasa yang kurang bijaksana.

12. "Mereka menumpas kami, hanya karena kami berbeda," sebuah suara seakan-akan menyembur karena mendapatkan kesempatan meletup. Semar tersenyum dalam diamnya. Dibiarkannya suara itu meluap-luap melepaskan amarah yang selama ini terpendam karena tak satu pun yang mampu mengeluarkannya.

Dari penuturannya itulah Semar memahami, betapa semuanya kini menjadi kacau balau. Mereka, para arwah itu, adalah pemuja Hyang Brahma, dewa penguasa api. Penyerang mereka adalah para pemuja Hyang Indra. Entah mengapa, sejak pergantian kekuasaan di Hastinapura, kedua paham itu begitu mudahnya berseteru, bahkan memuncak ketika upacara yang biasanya bisa dilakukan bersama-sama.

Dari sebuahh kesalahan kecil, bagaikan api yang membakar hutan, dalam sekejap menjadi pergolakan hebat, dan berakhir dengan penghangusan perbedaan (Manyura, hlm.15).

Fenomen sektarian ternyata bersumber pada sikap Yudhistira dalam memandang kepercayaan lain. Untuk mengungkapkan ide ini, NugrOHO mendemoralisasi tokoh Yudhistira sebagai pemimpin yang sektarian, yang kurang memiliki toleransi terhadap kepercayaan lain. Hal ini terlihat bagaimana Yudhistira kukuh terhadap kepercayaannya dan kurang bertoleransi terhadap kepercayaan lain. Nasehat Bhima tidak didengarkannya seperti kutipan berikut.

13. "Mereka, orang-orang Awangga itu adalah kaum penyembah Dewa Kalaludra. Ribuan tahun mereka berlindung di bawah naungannya, dan kini, dengan serta-merta Kanda memerintah $\neg$ kan agar mereka menyembah Hyang Darma, bagaimana mungkin mereka mau menerimanya?"

"Aku tidak ingin rakyatku berada dalam kegelapan, Bima."

"Kegelapan bagi siapa?"

"Apa maksudmu?"

"Hmmm, nyatanya, kita semua tak tahu apa-apa, tentang 'darma'." (Manyura, hlm. 56)

Masalah sektarian inilah pada dasarnya sebagai pemicu pemberontakan etnis Awangga terhadap penguasa. Mereka memiliki kepercayaan yang berbeda dengan pihak penguasa sehingga mereka dimarjinalkan, dan ditekan mengikuti agama kepercayaan penguasa. Perhatikan pula kutipan berikut.

14. "Mereka, orang-orang Awangga itu adalah kaum penyembah Dewa Kalaludra. Ribuan tahun mereka berlindung di bawah naungannya, dan kini, dengan serta merta Kanda memerintahkan agar mereka menyembah Hyang Darma, bagaimana mungkin mereka mau menerima?" (Manyura, hlm. 55)

Dalam menghadapi pemberontakan bangsa Awangga, Yudhistira mengambil jalan kekerasan yang bersifat kursif. Dia tidak memperhitungkan akar permasalahan terjadinya pemberontakan, dan dia menutup diri tehadap nasehat dan pertimbangan orang lain, tak terkecuali Bhima, saudaranya sendiri.

15. "Aku membutuhkan dukunganmu, bukan cercaanmu. Kau adalah saudaraku. Kau adalah orang yang ikut mendudukkanku di singgasana Hastina. Mengapa kau menyalahkan apa yang kulakukan?” (Manyura, hlm. 56)

Untuk memadamkan pemberontaan, dia menyuruh panglimanya, Sasikirana untuk menumpas semua orang yang terlibat pemberontakan, tak terkecuali yang dianggap provokatornya.

16. "Bawa kemari, hidup atau mati, siapa pun yang menggosokkan pemantiknya." (Manyura, hlm. 55) 
Bahkan saudarnya sendiri, Bhima, yang tidak sepaham dengannya dijebloskan ke penjara. Sasikirana pun meskipun banyak jasanya menumpas pemberontakan, karena keberadaannya dianggap merongrong kewibawaan Yudhistira, juga dimasukkan dalam penjara.

Demoralisasi tokoh Yudhistira semakin lengkap dengan pemberian karakter sebagai orang yang membanggakan diri. Hal ini disimbolkan dengan pembuatan patung dirinya.

17. Di samping Duryudana, tampak sebuah patung dari gading, dengan pahatan yang lebih halus, meskipun belum sempurna benar. Patung yang tampak agak dipaksakan untuk rampung itu adalah patung Prabu Kalimataya, atau Prabu Yudhistira. (Manyura, hlm. 29)

Perkataan "...Patung yang dipaksakan untuk rampung...." mengisyaratkan betapa pentingnya arti kebanggaan diri yang diekspresikan lewat simbol-simbol.

Masalah seks semakin melengkapi demoralisasi Yudhistira sebagai penguasa, yang dilukiskan sebabagi sosok yang melakukan selingkuh.

18. Oh, putri Pancala, putri sulung Drupada, mengapa sepasang mata indahmu menyaksikan suami dan adikmu memadu cinta? Termangu, seakan tak percaya pada apa yang dilihatnya, Drupadi limbung, dan tanpa sengaja tangannya menyenggol bokor kuningan. Suara berdentang itu membuat sepasang manusia itu terkejut. Srikandi segera menutupi tubuhnya dengan kain dan menangis. Tudhistira hanya menunduk lesu, sesaat setelah Drupadi menghilang tertelan arus perasaan yang luar biasa. (Manyura, hlm. 164)

Kehadiran Krisna sebagai sosok yang dipedulikan nasehatnya oleh Yudhistira pada dasarnya sebagai babak pencerahan. Esensinya bahwa seorang pemimpin dalam mengambil kebijakan dalam menjalankan pemerintahannya harus didasarkan pada realitas yang ada di masyarakat, tidak hanya didasarkan pada realita yang disodorkan oleh orang-orang disekitarnya, meskipun orang itu adalah kepercayaannya.

19. "Tetapi keputusan dan kebijaksanaan yang kau buat, bukan atas pertimbanganmu. Kau hanya menetapkan. Orang-orang sekelilingmu yang memberimu bahan untuk ditetapkan. Sadarlah dirimu bahwa kini bukan lagi Darmakusuma? (Manyura, hlm.162)

Penyadaran tokoh yang difokuskan sebagai akar konflik menjadi solusi pemecahan anarkisme yang cenderung berakibat pemarjinalan kelompok-kelompok tertentu. YANUSA NUGROHO memberikan pencerahan dalam Manyura melalui demoralisasi terhadap demoralisasi tokohnya seperti tercermin pada kutipan berikut ini.

20. Yudistira menitikkan airmata. Sudah sedemikian lamakah dirinya terkurung dalam sangkar emas Istana Hastinapura, sehingga penderitaan yang pernah dialaminya selama 13 tahun itu, seolah hilang dari jiwanya. Ke manakah hilangnya semua butir mutiara kehidupan yang diperolehnya dalam kesengsaraan masa pembuangan? (Manyura, hlm. 188)

\section{PENGANALOGIAN MANYURA}

Upaya pendekonstruksian kesakralan epos Mababarata yang bersifat hitam putih pada dasarnya sebagai bentuk kegelisaan YANUSA NugROHO terhadap krisis kepemimpinan yang memberikan dampak negatif terhadap kelangsungan hidup dan kehidupan bangsa. Kegelisaannya itu dituangkan melalui karyanya yang diberi judul Manyura.

Banyak bukti-bukti yang menunjukkan bahwa YANUSA NugROHO terilhami oleh krisis moral akibat anarkisme yang terjadi pada masa Orba. Istilah Kala atau Kawula Lami sebagai analogi dari Orba atau Orde Lama.

21. Dengan mudahnya berbagai tuduhan dilontarkan. Bahasa sandi "kala", kependekan 
dari “kawula lami”, atau pengikut setia Prabu Suyudana, dengan mudah terlontar dan menempel pada siapapun yang dianggap tidak sejalan dengan paham baru (Manyura, hlm.16)

Teks tersebut membuktikan adanya pemarjinalan terhadap kelompok kalah perang, yang disebut "kawula lami".

NugroHo tampaknya terobsesi dengan anarkisme yang timbul pada masa Soeharto berkuasa. "Kawula lami" tampak identik dengan orla atau orde lama pada masa rezim Soeharto sebagai orang pertama Indonesia. Pemberian istilah orla untuk lawan politik atau yang dianggap lawan sebagai upaya pemarjinalan kelompok tersebut, yang membedakan dengan kelompok orba yang superior dan memiliki keberpihakan terhadap penguasa. Pendekotomian tersebut pada dasarnya sebagai upaya untuk mengamankan keddukan rezim berkuasa.

Krisis moral seorang penguasa juga dijadikan isu menarik dalam Manyura. Kebanggaan terhadap tahta, ketakutan terhadap tergesernya kedudukan, arogansi, otoriterisme, sektarianisme, dan krisis moral lainnya pada Yudhistira yang ditokohkan sebagai penguasa tampak dianalogkn dengan tokoh rezim masa orba, yakni Soeharto. Kebanggaan terhadap diri yang disimbolkan dalam bentuk patung Yudhistira pada dasarnya identik dengan gambar Soeharto pada uang pecahan lima puluh ribuan pada jaman Orba. Isu sektarian dalam Manyura dapat pula diidentikkan dengan kasus Pancasila sebagai asas tunggal, yang ternyata berakibat adanya konflik. Meskipun konflik sebagai akibat sektarian dapat dinetralisasi, korban pun berjatuhan karena langkah yang dilakukan dengan agresi, tanpa dipertimbangkan lebih dalam akar permasalahannya. Penyelesaian masalah ini akan berdambak timbulnya permasalahan baru. Langkah-langkah ini tampak muncul sebagai salah satu kebijaksanaan pemerintah orba dalam menstabilisasikan negara. Arogansi terjadi dimana-mana dengan menggunakan istilah populer yang berbau litotes, yaitu "diamankan". Isu kebijakan ekonomi yang tidak populer dalam Manyura identik pula dengan menaikkan harga BBM dan listrik pada masa orba yang berdapmpak pada semakin merosotnya tingkat ekonomi masyarakat, khususnya masyarakat kecil. Sebenarnya masih banyak isu lain dalam Manyura yang identik dengan terjadinya anarkisme peralihan ORLA ke ORBA yang banyak memakan korban manusia dan harta benda.

\section{DISKUSI}

Permasalahan yang diangkat oleh YANUSA NugROHO melalui Manyura pada dasarnya bukan sekadar permasalahan penganalogan hasil pendekonstruksian dunia pewayangan terhadap dunia faktual yang menyangkut ketimpangan sosial dan kecarut-marutan perpolitikan pada masa pemerintahan ORBA, melainkan permasalahan yang sifatnya manusiawi dan universal. Dalam masa pemerintahan Reformasi saat ini pun terjadi permasalahan yang sama. Suksesi kepemimpinan yang selalu memberikan harapan bagi rakyat kecil atas standar kehidupan yang sejahtera bermuara kepada rasa tidak puas dan kecewa karena apa yang diimpikan tidak sesuai dengan yang diharapkan. Akhirnya, rakyat merasa kehidupannya tidak jauh berbeda dengan pemerintahan sebelumnya.

Subfimisme sejarah, degradasi intensitas penokohan, dan demoralisasi selalu muncul dalam kehidupan dan selalu terulang dari suksesi kepemimpinan yang satu ke kepemimpinan berikutnya, tanpa memberikan perubahan standar kehidupan yang lebih baik dan bahkan cenderung lebih buruk. Kewajiban berkorban demi bangsa dan negara adalah milik rakyat kecil. Namun, keberpihakan hidup sejahtera adalah milik kalangat atas, pengusaha, dan pejabat korup. Rakyat kecil tinggal meratapi nasibnya yang kurang beruntung. Roda pemerintahan berjalan melindas rakyat kecil dan meninggalkan mereka dengan segala harapan kosong belaka. Kondisi semacam itu tersimbolkan melalui pemerintahan Yudhistira dalam Manyura. 
Pada intinya Manyura mengandung pesan kepada pemimpin yang seharusnya jujur terhadap sejarah, tidak terdegradasi intensitas diri menjadi pemimpin yang imoral, dan menghindari demoralisasi. Ketiga pilar ini ditekankan dalam Manyura sebagai bekal seorang pemimpin yang memiliki kewenangan menggerakkan roda pemerintahan yang pro-rakyat.

\section{KESIMPULAN}

Pendekonstruksian dunia pewayangan yang dilakukan YANUSA NugROHO pada dasarnya sebagai upaya pemasukan ide-ide yang berupa anarkisme pascaperang melalui karya kreatif-imajinatif, yang berupa novel Manyura. Untuk mencapai tujuan tersebut, NUGROHO melakukan demoralisasi tokoh Yudhistira, yang menunjukkan tokoh putih dalam dunia pewayangan konvensional. Gugatan terhadap sumisifme sejarah pewayangan yang dilakukan NugROHO juga sebagai upaya pembenaran dekonstruksi wayang yang dilakukannya karena selama ini dunia pewayangan dipandang sebagai dunia yang penuh kesakralan. Pendegradasian intensits penokohan juga dilakkan untuk kepentingan penurunan intensitas tokoh-tokoh yang dominan seperti tokoh Arjuna, Bhima, dan lain-lain dalam dunia pewayangan sehingga seiring dengan itu intensitas tokoh kunci seperti Yudhistira menaik. Demoralisasi tokoh inilah yang menjadi sumber permasalahan sehingga ide-ide YANUSA NuGROHO dapat terwujud dengan mendekonstruksi pewayangan yang selama ini bersifat hitam-putih.

\section{DAFTAR PUSTAKA}

ANSHARI, HAFI.

1996. Kamus Psikologi. Surabaya: Usaha Nasional.

CHEW, SHIRlEy DAN DAVID Richards [ED.].

2010. A Concise Companion to Postcolo nial Literature. Southern Gate: Wl ley-Blackwell.
Nugroho, Yanusa.

2004. Manyura. Jakarta: Kompas.

Pendit, Nyoman S.

2004. Mahabharata. Jakarta: Gramedia Pustaka Utama.

RATNA, NYOMAN KUTHA.

2005. Sastra dan Cultural Studies: Repre sentasi Fiksi dan Fakta.

SALIM, PETER.

2002. The Contemporary English-Indo nesian Dictionary. Jakarta: Modern English Press.

SUSETYA, WAWAN.

2007. Bharatayuda. Yogyakarta: Kreasi Wacana. 